NBER WORKING PAPER SERIES

\title{
DID MEDICARE INDUCE PHARMACEUTICAL INNOVATION?
}

\author{
Daron Acemoglu \\ David Cutler \\ Amy Finkelstein \\ Joshua Linn \\ Working Paper 11949 \\ http://www.nber.org/papers/w11949
NATIONAL BUREAU OF ECONOMIC RESEARCH
1050 Massachusetts Avenue
Cambridge, MA 02138
January 2006

The views expressed herein are those of the author(s) and do not necessarily reflect the views of the National Bureau of Economic Research.

(C2006 by Daron Acemoglu, David Cutler, Amy Finkelstein, and Joshua Linn. All rights reserved. Short sections of text, not to exceed two paragraphs, may be quoted without explicit permission provided that full credit, including $\odot$ notice, is given to the source. 
Did Medicare Induce Pharmaceutical Innovation?

Daron Acemoglu, David Cutler, Amy Finkelstein, and Joshua Linn

NBER Working Paper No. 11949

January 2006

JEL No. H51, I18, O33, O38, L65

\section{ABSTRACT}

The introduction of Medicare in 1965 was the single largest change in health insurance coverage in U.S. history. Many economists and commentators have conjectured that the introduction of Medicare may have also been an important impetus for the development of new drugs that are now commonly used by the elderly and have substantially extended their life expectancy. In this paper, we investigate whether Medicare induced pharmaceutical innovations directed towards the elderly. Medicare could have played such a role only if two conditions were met. First, Medicare would have to increase drug spending by the elderly. Second, the pharmaceutical companies would have to respond to the change in market size for drugs caused by Medicare by changing the direction of their research. Our empirical work finds no evidence of a "first-stage" effect of Medicare on prescription drug expenditure by the elderly. Correspondingly, we also find no evidence of a shift in pharmaceutical innovation towards therapeutic categories most used by the elderly. On the whole, therefore, our evidence does not provide support for the hypothesis that Medicare had a major effect on the direction of pharmaceutical innovation.

Daron Acemoglu

Department of Economics

MIT, E52-380B

50 Memorial Drive

Cambridge, MA 02142-1347

and NBER

daron@mit.edu

David Cutler

Department of Economics

Harvard University

Cambridge, MA 02138

and NBER

dcutler@harvard.edu
Amy Finkelstein

Department of Economics

MIT E52 262F

50 Memorial Drive

Cambridge MA 02142

and NBER

afink@mit.edu

Joshua Linn

University of Illinois at Chicago

jlinn@uic.edu 


\section{Introduction}

The introduction of Medicare in 1965 was the single largest change in health insurance coverage in U.S. history. Providing nearly universal public health insurance coverage for the elderly, it is currently one of the largest health insurance programs in the world (Newhouse, 2002). Its introduction had dramatic effects on health insurance coverage and health care utilization for the elderly (Cook et al., 2005, Dow 2002, Finkelstein, 2005).

Since the introduction of Medicare, there has also been dramatic progress in the development of new pharmaceuticals. For example, Cutler and Kadiyala (2003) estimate that the development of new pharmaceuticals was responsible for about one-third of the pronounced decline in cardio-vascular disease mortality over the last-half century. Many economists have conjectured that Medicare provided part of the impetus for the development of new drugs, especially those most commonly used by the elderly (e.g., Lichtenberg, 2004, Cutler, 2004). However, there has been little systematic analysis of this hypothesis.

An impact of Medicare on pharmaceutical innovation would be consistent with recent empirical evidence of induced innovation in pharmaceuticals more generally. Acemoglu and Linn (2004) and Finkelstein (2004), for example, find that increases in expected demand for certain types of pharmaceuticals are associated with increases in clinical trials and FDA approvals for these products. Such an impact on innovation could also have implications for the cost of the new Medicare prescription drug benefit.

For Medicare to induce innovation in new pharmaceuticals, a necessary (but not sufficient) condition is for it to have increased the demand for prescription drugs among the elderly. Although prior to 2006 Medicare did not cover prescription drugs, it may have indirectly increased demand for prescription drugs since it covered physician care, which may be highly complementary with prescription drug use. In addition, any increase in pharmaceutical demand among the elderly caused by Medicare would have to be large enough to induce a change in the direction of technological change in this sector.

In this paper, we investigate the effect of Medicare on development of new pharmaceuticals for the elderly. Our strategy follows the logical steps laid out in the previous paragraph. In Section II, we look for an effect of Medicare on the demand for pharmaceuticals by the elderly. In Section III, we look for a change in the direction of pharmaceutical innovation after the introduction of Medicare. 
Our investigation provides no support for the conjecture that Medicare had a large effect on the direction of pharmaceutical innovation. We find no evidence that the introduction of Medicare is associated with an increase in drug consumption among the elderly. Consistent with this, we also find no evidence of an increase in approvals of new drugs that are more likely to be for diseases of the elderly after Medicare's introduction. Although data quality issues suggest some caution in interpreting the evidence, our reading is that there is no compelling case that Medicare induced significant pharmaceutical innovation.

\section{The Impact of Medicare on Drug Spending}

To investigate the impact of Medicare on demand for pharmaceuticals, we compare changes in drug spending for those aged 55-64 (interpreted as the control group not covered by the Medicare and referred to as the "nonelderly") to changes for elderly individuals aged 65-74. The 1963 and 1970 Surveys of Health Service Utilization and Expenditures, and their follow-up versions, the 1977 and 1987 National Medical Expenditure Surveys, contain individual-level data on total prescription drug expenditures. ${ }^{1}$ About one-fifth of total health care spending for individuals aged 65-74 in 1963 was for prescription drugs.

Our basic estimating equation is a simple differences-in-differences equation of the form:

$$
Y_{i a t}=\gamma_{t}+\alpha_{a}+\mathbf{X}_{i a t}^{\prime} \cdot \boldsymbol{\eta}+\beta \cdot\left(P O S T_{t} \cdot M_{i a t}\right)+\varepsilon_{i a t},
$$

where $Y_{\text {iat }}$ denotes prescription drug spending (in 2000 dollars) by individual $i$ in age group $a$ and year $t$; the $\gamma_{t}$ 's denote a full set of time (survey) dummies; the $\alpha_{a}$ 's denote a full set of age dummies; $\mathbf{X}_{i a t}$ is a vector of covariates (specifically, dummies for male, married, and three education categories). Finally $P O S T_{t}$ is a dummy indicating the introduction of Medicare, thus taking the value of 1 after 1965, and $M_{i a t}$ is a dummy variable for whether the individual is in the 65-74 age category and thus covered by Medicare. The coefficient of interest, $\beta$, measures the differential change in drug spending by the elderly after the introduction of Medicare.

Table 1 reports the results of estimating (1) with OLS. Odd-number columns report results without covariates, while even-numbered columns include the covariates $\mathbf{X}_{\text {iat }}$. Columns 1 and 2, which use the 1963 and 1970 data only, show no evidence that Medicare

\footnotetext{
${ }^{1}$ Spending data are based on individual self-reports, but attempts were made to verify insurance claims with third party payers. The first two surveys do not include usable population weights, so none of our estimates adjust for survey weights.
} 
is associated with an increase in prescription drug spending for the elderly relative to the nonelderly. For example, in column 2 with covariates, the estimate of $\beta$ is negative, though statistically insignificant, and corresponds to a $\$ 38$ decline in the spending by the elderly relative to nonelderly. The 95 percent confidence interval excludes an increase in prescription drug spending associated with Medicare of more than $\$ 21$, or more than 11 percent relative to the base of $\$ 209$. Using the same data and methodology, Finkelstein and McKnight (2005) find that the introduction of Medicare is associated with increases in the physician and hospital spending of individuals that are eligible for Medicare; unlike drugs, these services were covered by Medicare.

Columns 3 and 4 estimate the same specification expanding the "control group" to include younger individuals (ages 35-64), and the "treatment group" to include older indivdiuals (ages 65-84). They again indicate that there was no increase in the prescription drug expenditures of the elderly following the introduction of Medicare.

This evidence suggests that the necessary "first stage" for an induced innovation effect - namely an increase in expected market size - may not be present. However, at the time of Medicare's introduction, there was little in the way of effective pharmaceuticals for the major chronic illnesses of the elderly (e.g., Cutler and Kadiyala, 2003). It is therefore possible that pharmaceutical companies may have responded to the expected increases in demand that would occur if they produced new, more effective drugs for the newly-insured elderly.

To investigate this possibility, we looked at whether prescription drug spending for the elderly relative to the non-elderly increased with a lag after the introduction of Medicare. Columns 5 in 6 estimate the analogous specification to columns 1 and 2, but using data from 1963, 1970 and 1977. The estimate of $\beta$ remains negative and similar in magnitude to the estimates using only the 1963 and 1970 survey. Columns 7 and 8 add the 1987 survey. The estimate is once again insignificant and negative, but is now much closer to zero. Finally, if we modify (1) by replacing the $\beta \cdot\left(P O S T_{t} \cdot M_{i a t}\right)$ term with a more flexible specification with $\beta_{t} \cdot \gamma_{t} \cdot M_{\text {iat }}$ for $t=1970,1977$ and 1987, then, $\beta_{1987}$ is the only one of these three coefficients that is positive; all are statisitcally insignificant. ${ }^{2}$

\footnotetext{
${ }^{2}$ All non-reported results in the paper are available upon request.
} 


\section{The Impact of Medicare on Pharmaceutical Innovation}

We next examine whether drugs approved after the introduction of Medicare are for diseases that are more disproportionately concentrated in the elderly than drugs approved prior to Medicare's introduction. Acemoglu and Linn (2004) provide more detail on the data that we use. Data on approval of new drugs from 1950 through 1999 comes from the FDA. We can identify whether a new drug is a new molecular entity, which contains active ingredients that have not been previously marketed in the United States and therefore provides a measure of more radical innovations than the typical new drug approval. There are 7001 new drug approvals between 1950 and 1999, of which 725 are new molecular entities. Our key dependent variable is the number of new drug approvals (or new molecular entities) by year in each of 33 drug therapeutic classes. ${ }^{3}$

To identify the impact of Medicare on new drug approvals, we create a variable measuring the cross-sectional variation in the elderly's share of the consumption of drugs across therapeutic categories, denoted by $E S_{c}$ for category $c$. The basic logic of our approach is that if Medicare induced new innovation in drugs for the elderly, it would have more of an effect on new drug approvals in therapeutic categories that are disproportionately used by the elderly.

We measure $E S_{c}$ using 1996-1998 data from the Medical Expenditure Survey (MEPS). ${ }^{4}$ We compute this variable as the ratio of total prescription drug spending by individuals aged 65 and older on therapeutic class $c$ to total prescription drug spending for all ages in the same therapeutic class. The average of $E S_{c}$ is 0.34 , with a standard deviation of 0.21. Anticoagulants $\left(E S_{c}=0.69\right)$ are an example of a therapeutic category with a very

\footnotetext{
${ }^{3}$ Our 33 drug classes are relatively broad. For example, cardiac drugs are all one class. Since the elderly share is unlikely to vary within these more aggregated groupings, it is unlikely that we lose much power from not having a finer graduation of drug categories. Acemoglu and Linn (2004) provide a complete list of the 33 classes.

${ }^{4}$ Measuring $E S_{c}$ in 1996-1998 is a central limitation of our empirical strategy. Ideally, we would measure $E S_{c}$ before Medicare's introduction. Unfortunately, data on drug use by age and therapeutic category do not exist from this time period. To the extent that there have been substantial changes in the $E S_{c}$ over time, there will be downward attenuation bias in our estimates. Somewhat reassuringly, data from the National Ambulatory Care Survey (NAMCS) indicate that the age distribution of drug use is fairly similar between 1980 and 2000 (Acemoglu and Linn, 2004).

In general, we prefer the MEPS since the NAMCS is a nonrepresentative sample (only covering drugs prescribed by doctors in private practice), has a smaller sample size, and only provides information on the number of drugs consumed (rather than drug spending) in a given therapeutic class. However, all of our results remain essentially unchanged if we instead use data on the number of drugs used by age group from the 1980-1981 NAMCS to construct $E S_{c}$ (see Table 3 below).
} 
high elderly share, while antibiotics $\left(E S_{c}=0.15\right)$ are an example with a very low elderly share.

Because of our dependent variable is a count (of new drugs or new molecular entities), we estimate a conditional fixed effect Poisson model. We assume the following conditional mean function for $N_{c t}$, which denotes the number of new drug approvals (or new molecular entities) in therapeutic category $c$ in year $t$ :

$$
E\left[N_{c t} \mid \alpha_{c}, \bar{X}_{c}\right]=\exp \left(\alpha_{c}+\gamma_{t}+X_{c t}^{\prime} \cdot \phi+\beta_{t} \cdot \gamma_{t} \cdot E S_{c}\right)
$$

where $\alpha_{c}$ 's denote therapeutic category fixed effects, $\gamma_{t}$ 's denote year effects, $X_{c t}$ is $\log$ potential market size for therapeutic category $c$, and $\bar{X}_{c}$ denotes the mean of $X_{c t}$ for category $c$ over the sample period. ${ }^{5}$ The variables of interest are the interaction between year dummies and $E S_{c}$; this is parameterized flexibly, with a different coefficient $\beta_{t}$ for every year $t$.

We follow Jerry A. Hausman et al. (1984), and estimate the conditional logit transformation of equation (2):

$$
E\left[N_{c t} \mid \alpha_{c}, \bar{X}_{c}, \bar{N}_{c}\right]=\frac{\exp \left(\gamma_{t}+X_{c t} \cdot \phi+\beta_{t} \cdot \gamma_{t} \cdot E S_{c}\right)}{\sum_{\tau=1}^{T} \exp \left(\gamma_{\tau}+X_{c t} \cdot \phi+\beta_{\tau} \cdot \gamma_{\tau} \cdot E S_{c}\right)} \bar{N}_{c},
$$

which factors out the fixed effects, the $\alpha_{c}$ 's, and can be estimated consistently with quasimaximum likelihood (Wooldridge, 1999).

If Medicare had an effect on the direction of pharmaceutical innovation, we would expect $\beta_{t}$ 's to be positive at some point after 1965. The exact timing of the expected effect will depend on delays in the research and approval process. Delays of about 10 years, or even more, may well be plausible (DiMasi et al., 1991 Finkelstein, 2004).

Figures 1 and 2 show the pattern of $\beta_{t}$ 's for total new drug approvals and new molecular entities respectively. The figures make it clear that there is no statistically or economically significant change towards elderly therapeutic categories following Medicare, even when we look 10 or more years out to allow for a possibly lagged induced innovation effect.

\footnotetext{
${ }^{5}$ Potential market size in therapeutic class $c$ in year $t$ is constructed using the MEPS data described above to calculate spending by five-year age group in each therapeutic class and interpolated data from the IPUMS to estimate total population by age group in each year. See Acemoglu and Linn (2004) for more details. In practice, our key results results are not sensitive to whether or not we include this control.
} 
Table 2 reports the corresponding regression results from the estimation of (3). The first three columns report results for total drug approvals, while the next three columns are for new molecular entities. We report results with and without controlling for log potential market size. Finally, the last two columns estimate the log linear fixed effects model of Pakes and Griliches (1980), which may be easier to interpret than the conditional fixed effects Poisson model (though it is not consistent). This estimation method treats $N_{c t}=0$ as $N_{c t}=1$, and uses $\log N_{c t}$ on the left-hand side, and includes a dummy on the right-hand side when $N_{c t}=0$.

In all cases, to make the results easier to depict and interpret, the full set of year effect interactions with $E S_{c}$ are replaced with either a dummy for the post-Medicare period (i.e., Post-1965), or to allow for possible lags, with separate dummy variables for 1965-1975 and post-1975. The point estimates are always statistically insignificant and almost always negative, confirming the visual pattern apparent in Figures 1 and 2 that there is no evidence of an increase in drug approvals for the elderly after Medicare relative to before. ${ }^{6}$

Table 3 repeats the same regressions with an elderly share variable $E S_{c}^{\prime}$ constructed from the 1980 - 1981 NAMCS, and the results are very similar to those in Table 2. These results suggest that whether we measure elderly share in the mid to late 1990s or somewhat earlier (particularly using 1980s data from the NAMCS) has little effect on our results. However, as discussed above, the use of spending patterns in the 1960s may have been substantially different than those captured by our measures of $E S_{c}$ and $E S_{c}^{\prime}$, in which case there may be significant measurement error in our key right-hand side variable, biasing the coefficients of interest, the $\beta_{t}$ 's, towards zero. Nevertheless, the fact that our analysis in the previous section did not show much of an increase in drug spending of the elderly following Medicare makes us believe that the main reason for the absence of significant effect in Tables 2 and 3 is not data quality, but a lack of a significant effect on Medicare on the direction of pharmaceutical innovation.

Another potential limitation to our results is that we do not allow for differential income effects by drug class. If drugs that are less utilized by the elderly are also more

\footnotetext{
${ }^{6}$ In these regressions, the log of potential market size variable, which was the focus in Acemoglu and Linn (2004), is also insignificant. This is because the quality of this variable deteriorates as we go back in time, since it is constructed from detailed distribution of drug spending by age from the 1996-1998 MEPS. Naturally, this raises the question of whether such attenuation bias may also be responsible for the results in Tables 2 and 3. It is possible that the market size variable in Acemoglu and Linn (2004), which uses much more detailed drug use information by age than $E S_{c}$, may be more affected by attenuation bias.
} 
income elastic, incentives to develop them may have increased over time as incomes have risen.

Finally, while our estimates suggest that Medicare did not affect the development of new drugs for the elderly on average, they do not rule out the possibility that Medicare might have had a disproportionate effect on the relatively more important new drugs, for example, new anti-hypertensives drugs that have been important in reducing cardiovascular disease mortality (e.g., Cutler and Kadiyala, 2003). Although we cannot test the impact of Medicare on the development of new anti-hypertensives per se, Cook et al. (2005) find no evidence that the introduction of Medicare was associated with an increase in medication use for high blood pressure among the elderly with hypertension, which does not support an induced innovation effect of Medicare on anti-hypertensives either.

\section{Conclusion}

We found no evidence of an effect of Medicare on new innovation for pharmaceuticals for the elderly. Although this might appear to contradict findings by Finkelstein (2004) and Acemoglu and Linn (2004) concerning the effect of (potential) market size on pharmaceutical innovation, our interpretation, confirmed by the empirical results in Section III, is that there is no "first stage" of Medicare increasing the market size of drugs used by the elderly. Medicare covered hospital and doctor expenses but not pharmaceuticals, so the lack of a first stage is not entirely surprising. Looking forward over the next several decades, our findings leave open the interesting and important question of whether the new, 2006 Medicare Part D — which introduces Medicare prescription drug coverage — will have an induced innovation effect towards pharmaceuticals used by the elderly. 


\section{References}

Acemoglu, Daron, and Joshua Linn, "Market Size in Innovation: Theory and Evidence from the Pharmaceutical Industry." Quarterly Journal of Economics, CXIX (2004), 1049-1090.

Cook, Benjamin, Mary Beth Landrum, and Ellen Meara. 2005. "The impact of Medicare on Health Outcomes and Disparities Among the Elderly." Unpublished working paper.

Cutler, David. 2004. "Your Money or Your Life: Strong Medicine for America's Health Care System." Oxford University Press, New York: NY.

Cutler, David and Srikanth Kadiyala. 2003. "The Return to Biomedical Research: Treatment and Behavioral Effects" in Robert Topel and Kevin Murphy (eds). Measuring the Gains from Medical Research. Chicago: University of Chicago Press.

DiMasi, Joseph A., Ronald W. Hansen and Louis Lasagna. 1991. "Cost of Innovation in the Pharmaceutical Industry," Journal of Health Economics, X, 107-142.

Dow, William (2002). "The Introduction of Medicare: Effects on Elderly Health," unpublished mimeo.

Finkelstein, Amy. 2004. "Static and Dynamic Effects of Health Policy: Evidence from the Vaccine Industry." Quarterly Journal of Economics, May.

Finkelstein, Amy. 2005. "The Aggregate Effects of Health Insurance: Evidence from the Introduction of Medicare." NBER WP 11619.

Finkelstein, Amy and Robin McKnight. 2005. "What Did Medicare Do (And Was It Worth It)?". NBER WP 11609.

Hausman, Jerry, Bronwyn H. Hall and Zvi Griliches. 1984. "Econometric Models for Count Data with an Application to the Patents-R\&D Relationship," Econometrica, LII, 909-938.

Lichtenberg, Frank .2004. "Public Policy and Innovation in the U.S. Pharmaceutical Industry," in Public Policy and Entrepreneurship Douglas Holtz-Eakin and Harvey Rosen (eds.) MIT Press, Cambridge, MA.

Newhouse, Joseph. 2002. Pricing the Priceless: A Health Care Conundrum. MIT Press, Cambridge MA.

Pakes, Ariel and Zvi Griliches. 1980. "Patents and R\&D at the Firm Level: A First Look," Economic Letters, V, 377-381. 
Wooldridge, Jeffrey M. 1999. "Distribution-free Estimation of Some Nonlinear Panel Data Models," Journal of Econometrics, XC, 77-97. 
Figure 1: Impact of Medicare on Total New Drug Approvals

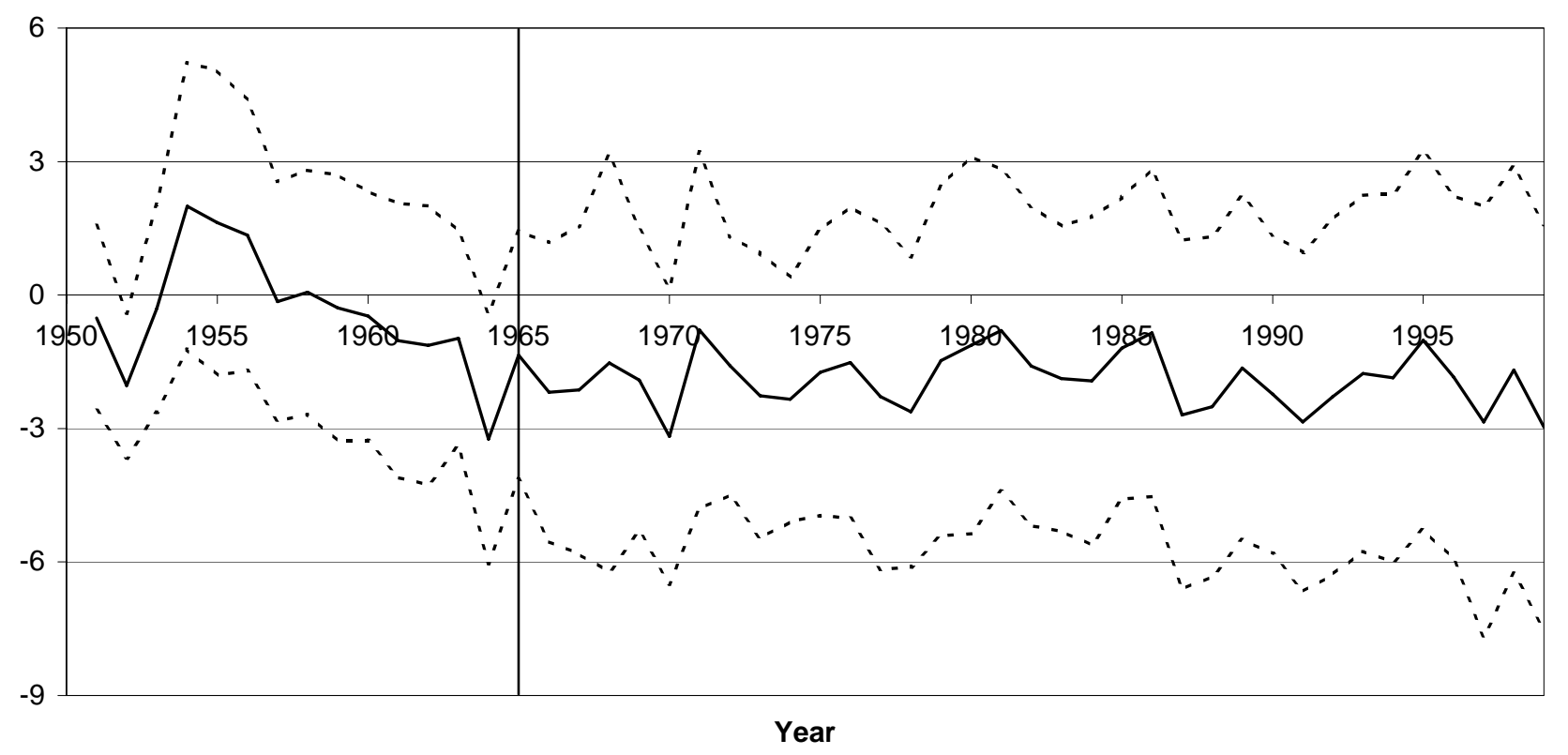

Notes: A Poisson conditional fixed effects model is estimated by quasi-maximum likelihood, where the dependent variable is total approvals by year and category. Data points are the estimated coefficients on the interactions of year dummies with the elderly market share. The coefficient on the omitted year (1950) is normalized to zero. The regression also includes year dummies and log market size. The dashed lines are the 95 percent confidence intervals, and the vertical line indicates the beginning of Medicare in 1965.

Figure 2: Impact of Medicare on New Molecular Entity Approvals

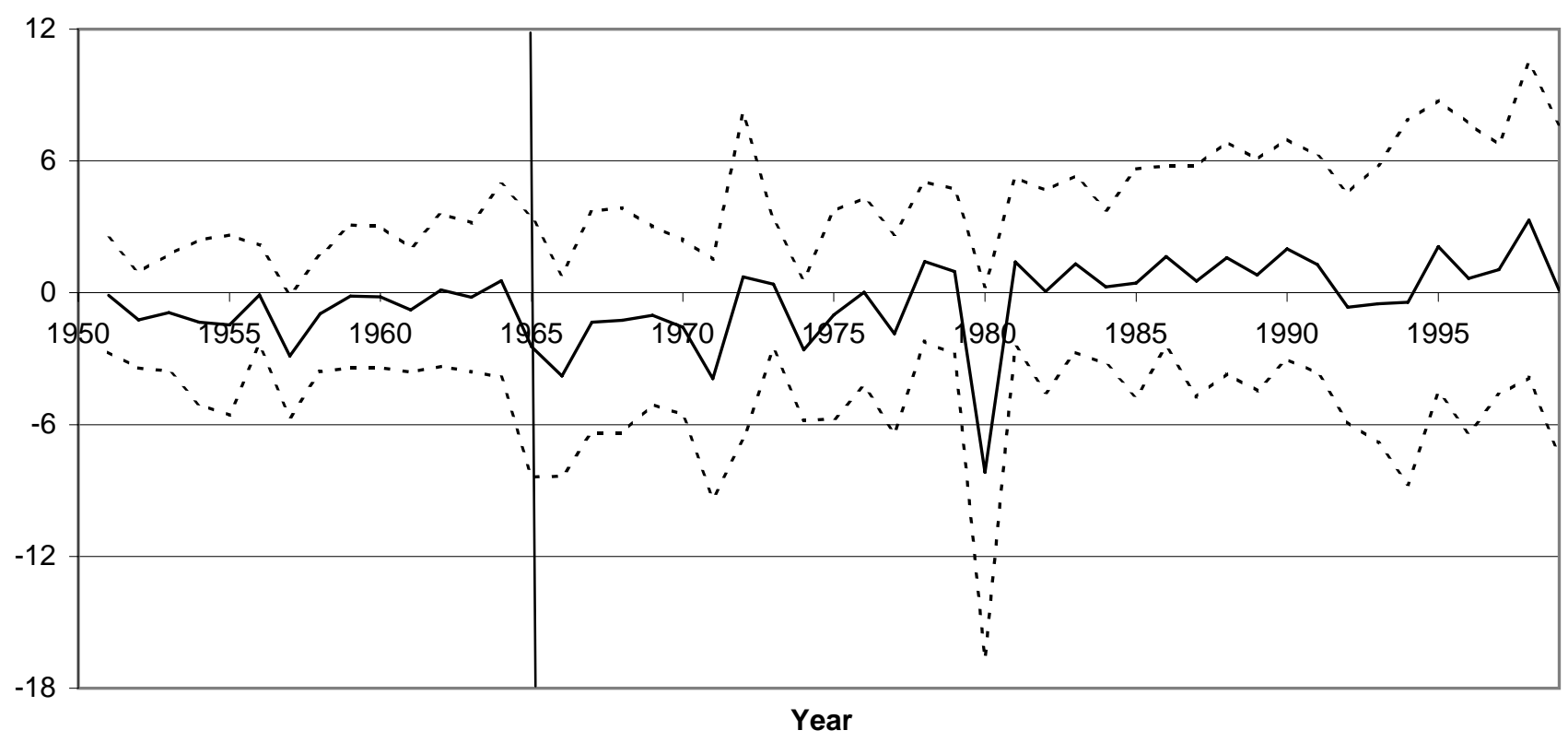

Notes: The graph is constructed similarly to Figure 1, except that the dependent variable is approvals of new molecular entities. 
Table 1

Prescription Drug Expenditure for Elderly vs. Non-Elderly, 1963-1987

\begin{tabular}{|c|c|c|c|c|c|c|c|c|}
\hline & (1) & (2) & (3) & (4) & (5) & (6) & (7) & (8) \\
\hline $\mathrm{M}_{\mathrm{iat}} \times \mathrm{POST}_{\mathrm{t}}$ & $\begin{array}{l}-39.11 \\
(31.25)\end{array}$ & $\begin{array}{l}-37.74 \\
(31.27)\end{array}$ & $\begin{array}{l}-15.74 \\
(23.76)\end{array}$ & $\begin{array}{l}-16.30 \\
(23.71)\end{array}$ & $\begin{array}{l}-28.13 \\
(26.08)\end{array}$ & $\begin{array}{l}-27.73 \\
(26.11)\end{array}$ & $\begin{array}{c}-9.52 \\
(25.37)\end{array}$ & $\begin{array}{l}-10.74 \\
(25.36)\end{array}$ \\
\hline $\begin{array}{l}\text { Number of } \\
\text { Observations }\end{array}$ & 2834 & 2834 & 5280 & 5280 & 9073 & 9073 & 15337 & 15337 \\
\hline $\begin{array}{l}\text { Mean of Dependent } \\
\text { Variable }\end{array}$ & 184.90 & 184.90 & 172.83 & 172.83 & 164.93 & 164.93 & 231.90 & 231.90 \\
\hline $\begin{array}{l}\text { Control for } \\
\text { Demographics }\end{array}$ & No & Yes & No & Yes & No & Yes & No & Yes \\
\hline $\begin{array}{l}\text { Age Range of } \\
\text { Sample }\end{array}$ & $55-74$ & $55-74$ & $45-84$ & $45-84$ & $55-74$ & $55-74$ & $55-74$ & $55-74$ \\
\hline Survey Years & \multicolumn{4}{|c|}{1963,1970} & \multicolumn{2}{|c|}{ 1963, 1970, 1977} & \multicolumn{2}{|c|}{$1963,1970,1977,1987$} \\
\hline
\end{tabular}

Notes: The dependent variable is total prescription drug expenditures, in 2000 dollars. $\mathrm{M}_{\mathrm{iat}}$ is a dummy variable equal to one for individuals 65 and older. POST is a dummy variable equal to one for the 1970, 1977 and 1987 NMES. Regressions in colunms 1, 2 and 5-8 include individuals aged 55-74, and regressions in columns 3 and 4 include individuals aged 35-74, from the corresponding surveys. All regressions include a full set of survey-year and age dummies. Demographics include gender, married, and education level. Observations are weighted by the reciprocal of the number of observations in the corresponding survey year. Robust standard errors in parentheses. 
Table 2

Impact of Medicare on New Drug Approvals, 1950-1999

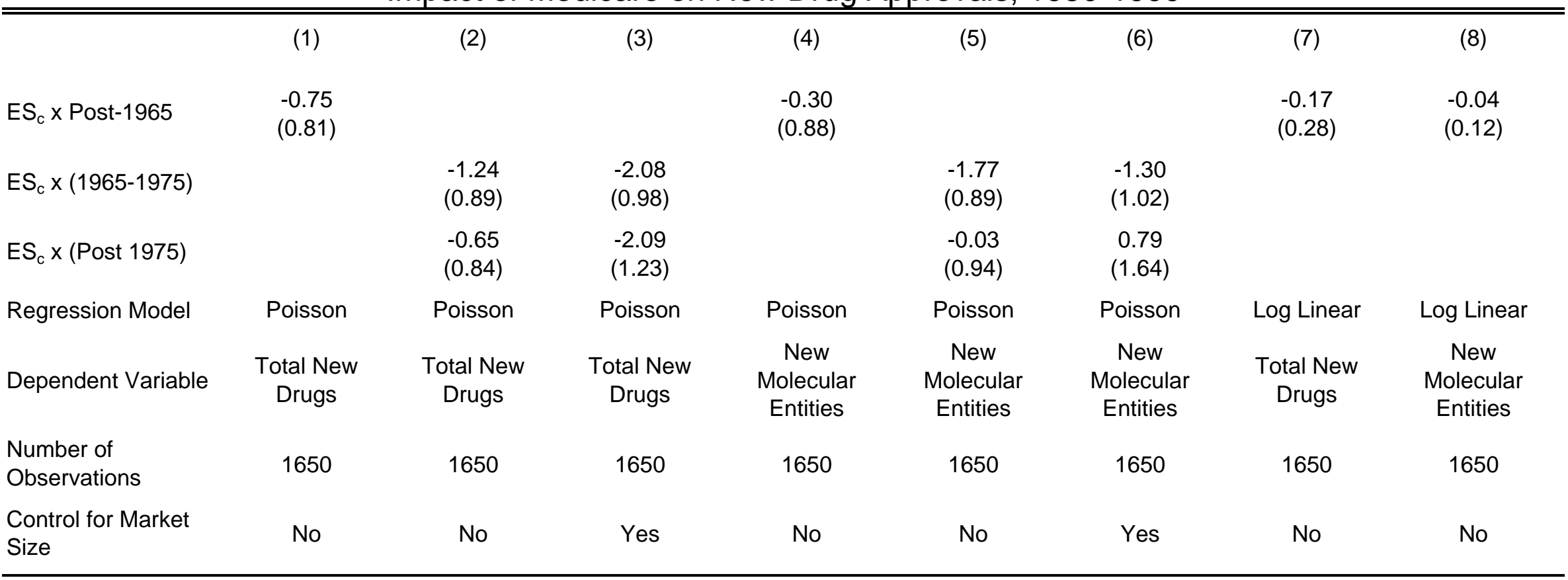

Notes: Standard errors are in parentheses, clustered by drug category. In columns 1-3 the dependent variable is total new drug approvals, by category and year; the dependent variable in columns 4-6 is approvals of new molecular entities. $E_{c}$ is the share of total drug expenditure in category $c$ accounted for by individuals aged 65 and older. (Post-1965) is a dummy variable equal to one for years 1965-1999; 1965-1975 is a dummy variable equal to one during the indicated years; and Post-1975 is a dummy variable equal to one for years 1975-1999. The Poisson model is estimated by quasi-maximum likelihood in columns 1-6 (see text). The log linear fixed effects model is estimated by ordinary least squares in columns 7 and 8 (see text). All regressions include a full set of year dummies, and columns 7 and 8 include a full set of category dummies. Columns 3 and 6 also control for log market size (see text). 
Table 3

Impact of Medicare on New Drug Approvals using NAMCS, 1950-1999

\begin{tabular}{|c|c|c|c|c|c|c|c|c|}
\hline & (1) & (2) & (3) & (4) & (5) & (6) & (7) & (8) \\
\hline ES $_{c}^{\prime} \times$ Post-1965 & $\begin{array}{l}-0.82 \\
(1.07)\end{array}$ & & & $\begin{array}{l}-0.44 \\
(1.03)\end{array}$ & & & $\begin{array}{c}0.32 \\
(0.48)\end{array}$ & $\begin{array}{l}-0.12 \\
(0.22)\end{array}$ \\
\hline$E_{c}^{\prime} \times(1965-1975)$ & & $\begin{array}{l}-1.90 \\
(0.97)\end{array}$ & $\begin{array}{l}-2.44 \\
(1.05)\end{array}$ & & $\begin{array}{l}-1.96 \\
(1.06)\end{array}$ & $\begin{array}{l}-1.64 \\
(1.16)\end{array}$ & & \\
\hline$E_{C}^{\prime} x$ (Post 1975) & & $\begin{array}{l}-0.61 \\
(1.13)\end{array}$ & $\begin{array}{l}-1.60 \\
(1.47)\end{array}$ & & $\begin{array}{l}-0.16 \\
(1.08)\end{array}$ & $\begin{array}{c}0.50 \\
(1.34)\end{array}$ & & \\
\hline Regression Model & Poisson & Poisson & Poisson & Poisson & Poisson & Poisson & Log Linear & Log Linear \\
\hline Dependent Variable & $\begin{array}{l}\text { Total New } \\
\text { Drugs }\end{array}$ & $\begin{array}{l}\text { Total New } \\
\text { Drugs }\end{array}$ & $\begin{array}{l}\text { Total New } \\
\text { Drugs }\end{array}$ & $\begin{array}{l}\text { New } \\
\text { Molecular } \\
\text { Entities }\end{array}$ & $\begin{array}{c}\text { New } \\
\text { Molecular } \\
\text { Entities }\end{array}$ & $\begin{array}{c}\text { New } \\
\text { Molecular } \\
\text { Entities }\end{array}$ & $\begin{array}{l}\text { Total New } \\
\text { Drugs }\end{array}$ & $\begin{array}{c}\text { New } \\
\text { Molecular } \\
\text { Entities }\end{array}$ \\
\hline $\begin{array}{l}\text { Number of } \\
\text { Observations }\end{array}$ & 1650 & 1650 & 1650 & 1650 & 1650 & 1650 & 1650 & 1650 \\
\hline $\begin{array}{l}\text { Control for Market } \\
\text { Size }\end{array}$ & No & No & Yes & No & No & Yes & No & No \\
\hline
\end{tabular}

Notes: Standard errors are in parentheses, clustered by drug category. $\mathrm{ES}_{\mathrm{c}}{ }^{\prime}$ is the share of drug use in category $c$ accounted for by individuals aged 65 and older, computed using the 1980 and 1981 NAMCS. All other variables and specifications are the same as in Table 2. 